\title{
BARREIRAS NA INCLUSÃO DA PESSOA COM DEFICIÊNCIA NO MERCADO DE TRABALHO
}

\section{ARTIGO ORIGINAL}

SILVA, Dayana Belo da ${ }^{1}$

SILVA, Dayana Belo da. Barreiras na inclusão da pessoa com deficiência no mercado de trabalho. Revista Científica Multidisciplinar Núcleo do Conhecimento. Ano 06, Ed. 07, Vol. 10, pp. 123-136. Julho de 2021. ISSN: 2448-0959, Link de acesso: https://www.nucleodoconhecimento.com.br/lei/pessoa-com-deficiencia, DOI: 10.32749/nucleodoconhecimento.com.br/lei/pessoa-com-deficiencia

\section{RESUMO}

Este artigo apresenta uma reflexão sobre as dificuldades e desafios encontrados por pessoas com algum tipo de deficiência na inserção no mercado de trabalho. Este estudo tem como questão norteadora: por que mesmo com a criação de leis, que asseguram plenos direitos às pessoas com deficiência, barreiras ainda são encontradas na inclusão das pessoas com deficiência no mercado de trabalho? Tal questão será abordada através de levantamento bibliográfico. $O$ artigo tem por objetivo a compreensão da dificuldade de inclusão mesmo com as evoluções ao longo dos anos e a existência de leis na legislação brasileira. Observa-se que este tema é de grande relevância, uma vez que busca mudar a mentalidade preconceituosa instalada na sociedade e contribuir para uma sociedade mais justa.

Palavras-Chave: pessoas com deficiência, barreiras, inclusão, mercado de trabalho.

\footnotetext{
${ }^{1}$ Pós-graduação em Planejamento Estratégico / Graduação em Administração.
} 


\section{INTRODUÇÃO}

É indiscutível a importância da inclusão de pessoas com deficiência - PcD no mercado de trabalho. Demorou muito tempo para a sociedade ter a percepção de valorizar as pessoas com necessidades especiais. No que diz respeito às pessoas com deficiência, o preconceito ainda tende a ser superado de maneira a possibilitarIhes a inclusão definitiva.

Segundo dados do censo do IBGE (Instituto Brasileiro de Geografia e Estatística) no Brasil, quase $24 \%$ da população é composta por pessoas que possuem algum tipo de deficiência. De acordo com o último Censo realizado em 2010, o Brasil possui 45 milhões de pessoas com deficiência. Em um contexto geral simboliza um número expressivo e requer atenção. (IBGE, 2010)

Pessoas que possuem necessidades especiais são divididas nas categorias: física, auditiva, visual, mental e múltipla. No Brasil, a "Lei de Cotas", que será abordada no presente trabalho, institui a exigência de que organizações com cem ou mais colaboradores completem uma parte de seus cargos e funções com PcD.

De acordo com Sassaki (2003), os portadores de deficiência têm os mesmos direitos e deveres que as outras pessoas. Com os anos, receberam siglas diferentes para a sua definição. No início, chamados de PPD (Pessoas Portadora de Deficiência), após, tiveram sua denominação alterada para PNE (Pessoa com Necessidades Especiais). Atualmente recebem o nome de PcD (Pessoa com Deficiência).

Justifica-se o estudo do presente tema pelos entraves encontrados pelas PCD para alcançarem colocação no mercado de trabalho, assim como a designação do termo correto dos deficientes, que devem ser tratadas com dignidade e respeito.

Sendo assim, este trabalho pretende destacar a seguinte questão: por que mesmo com a criação de leis, que asseguram plenos direitos às pessoas com deficiência, barreiras ainda são encontradas na inclusão das pessoas com deficiência no 
mercado de trabalho? Atentando ao fato que a pessoa com deficiência também tem o seu lugar na sociedade, portanto, deve ser respeitada como os demais cidadãos e merecem as mesmas oportunidades.

\title{
2. EVOLUÇÃO HISTÓRICA
}

Por muitos anos o deficiente físico foi discriminado pela sociedade e até mesmo por seus próprios familiares. Os registros mais antigos mencionam que pessoas com alguma deficiência simplesmente eram exterminadas. Platão, no livro A República, já tratava do planejamento das cidades gregas indicando os deficientes para serem banidos.

A República, Livro IV, 460 c - Pegarão então os filhos dos homens superiores, e levá-los-ão para o aprisco, para junto de amas que moram à parte num bairro da cidade; os dos homens inferiores, e qualquer dos outros que seja disforme, escondê-los-ão num lugar interdito e oculto, como convém (GUGEL, 2007, p. 63).

O filósofo grego Aristóteles (384-322 a.C), no livro "A Política", também são encontrados os mesmos relatos de eliminação das pessoas nascidas com alguma deformidade.

\begin{abstract}
A Política, Livro VII, Capítulo XIV, 1335 b - Quanto a rejeitar ou criar os recém-nascidos, terá de haver uma lei segundo a qual nenhuma criança disforme será criada; com vistas a evitar o excesso de crianças, se os costumes das cidades impedem o abandono de recém-nascidos deve haver um dispositivo legal limitando a procriação se alguém tiver um filho contrariamente a tal dispositivo, deverá ser provocado o aborto antes que comecem as sensações e a vida (a legalidade ou ilegalidade do aborto será definida pelo critério de haver ou não sensação e vida). (ARISTOTELES, 1985)
\end{abstract}

As leis romanas da Antiguidade não favoreciam às pessoas que nasciam com deficiência, aos pais era permitido matar as crianças com deformidades físicas pela prática do afogamento ou abandonar seus filhos. Os sobreviventes passavam a fazer parte de circos para o entretenimento dos homens ricos.

RC: 91995

Disponível em: https://www.nucleodoconhecimento.com.br/lei/pessoa-comdeficiencia 
Com o surgimento do cristianismo ainda no Império Romano a doutrina voltava-se para a caridade e o amor entre as pessoas, nesse período é que surgiram os primeiros hospitais de caridade que abrigavam indigentes e pessoas com deficiências.

A Revolução Industrial, no fim do século XVIII, tomou grande impulso. O trabalho artesanal foi substituído pelo assalariado com o uso de máquinas. A máquina era priorizada em relação ao homem. Neste novo cenário, evidencia-se a abordagem de Taylor, o "pai da administração científica", seu foco era a eficiência e eficácia operacional na administração industrial. Os trabalhadores eram submetidos a repetitivas funções, gerando fadiga e estresse, sendo o corpo físico o principal ponto de impacto dos prejuízos do trabalho.

A Revolução Industrial foi a maior responsável pela inclusão social das PCDs, segundo Aranha (1995), exigente de profissionais capacitados para produzir, a preocupação em formar deficientes produtivos também entrou em questão.

\begin{abstract}
Considerando-se que é no cenário das relações sociais interpessoais que se dá a apreensão do real, a construção do conhecimento, o desenvolvimento do homem e a construção da subjetividade e da própria sociedade, a exclusão do deficiente inviabiliza tanto para os indivíduos, deficientes e não deficientes quanto para a sociedade, o trato das diferenças enquanto elementos constitutivos da própria natureza humana. (ARANHA 1995, p. 70)
\end{abstract}

No Brasil, início do século XIX, os soldados acometidos por algum tipo de deficiência na guerra, por causa dos conflitos entre militares, eram abrigados por entidades, exemplo do Asilo dos Inválidos da Pátria, que dava assistência aos militares lesados pela guerra. Ainda no século XIX, surgiram as primeiras iniciativas de atenção à PCD: Hospício Pedro II[2], Instituto dos Meninos Cegos[3] e o Instituto de Surdos e Mudos[4], durante esse recorte histórico percebemos que os projetos educacionais atendiam os deficientes com cegueira ou surdes.

No século XX, com o surgimento da Primeira Guerra Mundial (1914-1918), uma significativa quantidade de homens foi chamada para servir e lutar. Com o fim da

RC: 91995

Disponível em: https://www.nucleodoconhecimento.com.br/lei/pessoa-comdeficiencia 
guerra, os homens que voltavam das batalhas com mutilações, elevaram o número de pessoas com deficiência. Os ex combatentes eram submetidos à reabilitação. No século XX é que houve, de fato, uma mobilização maior atender as pessoas com deficiência e sua inserção na sociedade. O período foi marcado por importantes avanços para as pessoas com deficiência, os instrumentos utilizados pelos deficientes foram aperfeiçoados, como a cadeira de rodas, bengalas, entre outros.

Ainda no século XX, a partir da Constituição Federal de 1988, que proporcionou a igualdade de direito ao todos os cidadãos, trazendo garantias e direitos irrevogáveis as pessoas portadoras de doenças nunca abordadas, introduzindo o grupo como parte integrante da sociedade e a inserção ao mercado de trabalho.

Art. 23. É competência comum da União, dos Estados, do Distrito Federal e dos Municípios:

(...) II - cuidar da saúde e assistência pública, da proteção e garantia das pessoas portadoras de deficiência;

Art. 24. Compete à União, aos Estados e ao Distrito Federal legislar concorrentemente sobre:

(...) XIV - proteção e integração social das pessoas portadoras de deficiência.

(CF/1988, Título III - Da Organização do Estado - Capítulo II - Da União) (BRASIL, 1988)

Nos dias de hoje, em pleno século XXI, como tem sido a evolução da inclusão do deficiente físico na sociedade? Ao acompanharmos este movimento histórico, são inegáveis as evoluções e as conquistas, mas não podemos deixar de fazer uma reflexão a respeito da aceitação das pessoas com deficiência no Brasil e os desafios encontrados. Que desafios são esses? A barreira do preconceito vigente, a devida qualificação profissional para os portadores de necessidades especiais, oportunidades de emprego, promoção da acessibilidade, entre outros.

Historicamente, vem ocorrendo uma evolução, diferentemente dos períodos anteriores, o século XXI é marcado por um grande movimento de inclusão da 
pessoa com deficiência no mercado de trabalho. Com a legislação formada e em constantes mudanças, cada dia mais empresas procuram se enquadrar na chamada Lei de Cotas, que obriga a contratação de $2 \%$ a $5 \%$ de colaboradores com deficiência.

\section{POR QUE A LEI?}

Em 1991, com a Lei 8.231, que regulamentou a Lei de Cotas para as PCDs, estabeleceu a obrigatoriedade de que empresas com cem ou mais empregados preencham uma parcela de seus cargos com pessoas com deficiência. De acordo com esta lei, no art. $93^{\circ}$, incisos de I a IV, ficou determinando que:

$$
\begin{aligned}
& \text { A empresa com } 100 \text { (cem) ou mais empregados está obrigada a } \\
& \text { I - até } 200 \text { empregados....................2\%; } \\
& \text { II - de } 201 \text { a 500...............................3\%; } \\
& \text { III - de } 501 \text { a } 1.000 \ldots \ldots \ldots \ldots \ldots \ldots \ldots . . . . .4 \% \text {; } \\
& \text { IV - de } 1.001 \text { em diante. ................5\%" } \\
& \text { (BRASIL, 1991). }
\end{aligned}
$$
preencher de $2 \%$ (dois por cento) a $5 \%$ (cinco por cento) dos seus cargos com beneficiários reabilitados ou pessoas portadoras de

A Lei 8.213 da Legislação Brasileira, em seu parágrafo primeiro, art. 93 estabelece:

A dispensa do empregado deficiente nos contratos indeterminados, só pode ocorrer quando outro candidato também PCD, for contratado no lugar do dispensado. Se esta não ocorrer, o empregado original deve ser reintegrado mesmo em condições de trabalho insatisfatórias (BRASIL, 1991).

A inclusão de pessoas deficientes na sociedade brasileira ainda esbarra no preconceito e se torna uma barreira que cria obstáculo como a falta de oportunidade no mercado de trabalho. 
Mesmo com a existência da lei que garante vaga reservada a pessoa com deficiência, as organizações ainda encontram barreiras para o preenchimento das vagas, devido à alguns entraves como o preconceito, a falta de qualificação profissional, a oportunidade de emprego e acessibilidade.

\section{A DEFICIÊNCIA}

Deficiência é o nome que define a falta de uma estrutura fisiológica, psíquica ou anatômica, o termo "PcD" é dado ao se referir a uma pessoa que tenha algum tipo de deficiência, que normalmente necessita de algum tipo de atendimento especial, exemplo da fisioterapia, de modo que a pessoa desenvolva suas potencialidades.

A Convenção Sobre dos Direitos da Pessoa com Deficiência (2007), dispõe no art. 10: "pessoas com deficiência são aquelas que tem impedimento de longo prazo de natureza física, mental, intelectual ou sensorial, o qual, em interação com uma ou mais barreiras, pode obstruir sua participação plena e efetiva na sociedade em igualdade de condições com as demais pessoas".

Na Legislação Brasileira, os tipos de deficiência estão categorizados no Decreto no 3.298. No art. 4, enquadram-se nas seguintes categorias do decreto:

I - Deficiência física - alteração completa ou parcial de um ou mais segmentos do corpo humano, acarretando o comprometimento da função física, apresentando-se sob a forma de paraplegia, paraparesia, monoplegia, monoparesia, tetraplegia, tetraparesia, triplegia, triparesia, hemiplegia, hemiparesia, ostomia, amputação ou ausência de membro, paralisia cerebral, nanismo, membros com deformidade congênita ou adquirida, exceto as deformidades estéticas e as que não produzam dificuldades para o desempenho de funções;

II - Deficiência auditiva - perda bilateral, parcial ou total, de quarenta e um decibéis $(\mathrm{dB})$ ou mais, aferida por audiograma nas frequências de $500 \mathrm{HZ}, 1.000 \mathrm{HZ}, 2.000 \mathrm{~Hz}$ e $3.000 \mathrm{~Hz}$;

III - Deficiência visual - cegueira, na qual a acuidade visual é igual ou menor que 0,05 no melhor olho, com a melhor correção óptica; a baixa visão, que significa acuidade visual entre 0,3 e 0,05

RC: 91995

Disponível em: https://www.nucleodoconhecimento.com.br/lei/pessoa-comdeficiencia 
no melhor olho, com a melhor correção óptica; os casos nos quais a somatória da medida do campo visual em ambos os olhos for igual ou menor que 60o; ou a ocorrência simultânea de quaisquer das condições anteriores

IV - Deficiência mental - funcionamento intelectual significativamente inferior à média, com manifestação antes dos dezoito anos e limitações associadas a duas ou mais áreas de habilidades adaptativas, tais como: a) comunicação; b) cuidado pessoal; c) habilidades sociais; d) utilização dos recursos da comunidade; e) saúde e egurança; f) habilidades acadêmicas; g) lazer; e h) trabalho;

V - Deficiência múltipla - associação de duas ou mais deficiências. Numa simples leitura, percebe-se que os conceitos são incompatíveis e apenas um deverá prevalecer (BRASIL, 1999).

\subsection{O DEFICIENTE}

De acordo com a Convenção sobre os Direitos das Pessoas com Deficiência:

As pessoas com deficiência são aquelas que têm impedimentos de longo prazo de natureza física, mental, intelectual ou sensorial, os quais, em interação com diversas barreiras, podem obstruir sua participação plena e efetiva na sociedade em igualdades de condições com as demais pessoas (CPDP/ONU, 2007, p. 16).

O decreto 3.298, que regulamenta a Lei $n^{0} 7.853$ sobre a Política Nacional para a Integração da Pessoa Portadora de Deficiência, no art. 3 da Lei, dispõe:

Incapacidade - uma redução efetiva e acentuada da capacidade de integração social, com necessidade de equipamentos, adaptações, meios ou recursos especiais para que a pessoa portadora de deficiência possa receber ou transmitir informações necessárias ao seu bem-estar pessoal e ao desempenho de função ou atividade a ser exercida (BRASIL, 1999).

\section{BAREIRAS NA INCLUSÃO DE PCD NO MERCADO DE TRABALHO}

Os deficientes físicos enfrentam barreiras diariamente, barreiras físicas, obstáculos de emprego, falta de acessibilidade, entre outros. Contudo, nos dias de hoje, as atitudes da população brasileira em relação ao deficiente físico são os obstáculos 
mais complexos para transpor. As barreiras encontradas pelas pessoas com deficiência vão além de barreiras arquitetônicas, que são os obstáculos que impedem as pessoas de desfrutarem e ocuparem o espaço físico. Hoje, o deficiente físico ainda precisa lidar com a barreira social, relativa aos processos de inclusão e exclusão social de grupos de pessoas. Algumas barreiras dificultam essa classe de pessoas a chegarem no mercado de trabalho como o preconceito, a falta de qualificação profissional, a falta de oportunidade de emprego e por fim, mas não menos importante, a acessibilidade.

\subsection{O PRECONCEITO}

Mesmo com a crescente transformação da sociedade ao longo dos anos, pessoas com algum tipo de deficiência ainda são discriminadas e excluídas do mercado de trabalho.

Ainda são grandes as barreiras para inclusão de pessoas com deficiência no mercado de trabalho, barreiras como o preconceito e a ignorância, no sentido de ausência de conhecimento.

Sobre este tema Ribas (1996) afirma:

Ignorância não é atributo apenas dos mais pobres ou dos que têm menos estudo. É algo que está presente em todas as camadas sociais, em muitas famílias, grupos de empresários, funcionários do governo (federal, estadual ou municipal) e, até mesmo, em muitos médicos que não se especializaram em reabilitar pessoas portadoras de deficiência ou que não têm prática no tratamento de algumas restrições do corpo leves ou profundas (RIBAS, 1996, p.63).

Sobre o preconceito Ribas (1996) afirma que:

Em maior ou menor grau, todos nós somos preconceituosos. Ninguém escapa. Nem mesmo pesquisadores universitários e acadêmicos. Isso porque a primeira impressão é sempre preconceituosa, já que está relacionada a algo com o qual jamais tivemos contato. É verdade que os pesquisadores universitários e acadêmicos (sobretudo os que trabalham com as ciências humanas)

RC: 91995

Disponível em: https://www.nucleodoconhecimento.com.br/lei/pessoa-comdeficiencia 
reelaboram o preconceito que existe dentro deles, até mesmo para conseguir pesquisar. E aí, então, conseguem enxergar o que está por trás da primeira imagem (RIBAS, 1996, p.64).

A inserção de pessoas com algum tipo de deficiência no mercado ocupacional trabalhista, busca trazer a diferença para dentro das organizações, de forma a combater o preconceito e admitir a igualdade social entre os cidadãos, é uma atitude a ser adotada como valor e prática nos negócios.

Sendo assim, dada a importância da inclusão de pessoas com deficiência nas empresas, este trabalho dedica-se expandir os esclarecimentos e desafios a respeito da possibilidade da contração da mão de obra específica de PcD.

\subsection{FALTA DE QUALIFICAÇÃO PROFISSIONAL}

Muitas empresas alegam a não contratação de $\operatorname{PcD}$ devido à ausência de profissionais capacitados ou qualificados. A falta de formação básica também é um dos desafios para garantir a inclusão de deficientes no mercado de trabalho. A educação inclusiva (inclusão das pessoas com necessidades especiais na rede regular de ensino), é fundamental para que os alunos com suas necessidades educacionais especiais tenham condições de construir seu aprendizado, comum a todos os alunos. O Relatório Mundial Sobre a Deficiência, publicado pela Organização Mundial da Saúde em 2011, aponta que crianças com deficiência têm menor probabilidade de frequentar escolas, enfrentando assim oportunidades limitadas de formação de capital humano e obtendo menos oportunidades de emprego e menor produtividade durante a vida adulta.[5]

A Constituição Federal estabelece que o acesso à educação do deficiente físico deve ser assegurado pelo Estado através de assistência educacional capacitada, de acordo com o artigo 208, inciso III:

Com o mercado de trabalho estando cada vez mais exigente na contratação de profissionais, as organizações estão cada vez mais rigorosas quando se trata em 
preencher a lacuna entre competências e habilidades, buscam profissionais capacitados e que possuam habilidades para a realização das tarefas. O deficiente é capaz de ocupar cargos e desempenhar um excelente trabalho, basta ele estar capacitado profissionalmente para desempenhar a função pela qual foi contratado.

Pastore (2000) explica que a falta de qualificação profissional é um dos motivos principais para que os portadores de necessidades especiais ocupem um nível ainda pequeno no mercado de trabalho.

O fenômeno é mundial. Em todos os países, o mercado de trabalho é mais restrito aos portadores de deficiência. As causas são múltiplas. De um lado, a falta de qualificação. De outro, a falta de esclarecimento. E, por cima de tudo, a falta de estímulos que facilitam a sua contratação (PASTORE, 2000, p. 71).

\subsection{OPORTUNIDADE DE EMPREGO}

Mesmo com a criação da Lei 8.231, que estabelece a Lei de Cotas para as pessoas com alguma deficiência, elas ainda encontram barreiras no mercado. De acordo com o levantamento I. Social - Expectativas e Percepções Sobre o Mercado de Trabalho Para PCDS realizada no ano de $2017,79 \%$ dos das empresas que responderam à pesquisa declararam que as empresas contratam pessoas com deficiência com foco unicamente no cumprimento da Lei de Cotas. [6]

Muitas vezes a pessoa portadora de alguma deficiência encontra dificuldades para serem inseridas nas organizações devido ao receio das empresas quanto à adaptação das limitações do funcionário ao ambiente de trabalho. A baixa qualidade das vagas que são oferecidas aos deficientes também é uma grande barreira para a inclusão do deficiente. As vagas, em sua maioria, são de níveis operacionais, como, auxiliar e assistente, do ponto de vista salarial pouco atrativas.

RC: 91995

Disponível em: https://www.nucleodoconhecimento.com.br/lei/pessoa-comdeficiencia 


\subsection{ACESSIBILIDADE}

No Brasil, a acessibilidade não se trata de um luxo, é uma necessidade enfrentada por pessoas com dificuldade visual e físico-motora. A falta de fiscalização dificulta o acesso das pessoas com deficiência na maioria dos locais públicos.

A Lei 10.098 da Constituição Federal em seu art. 1, dispõe:

Art. $1^{\circ}$ Esta Lei estabelece normas gerais e critérios básicos para a promoção da acessibilidade das pessoas portadoras de deficiência ou com mobilidade reduzida, mediante a supressão de barreiras e de obstáculos nas vias e espaços públicos, no mobiliário urbano, na construção e reforma de edifícios e nos meios de transporte e de comunicação (BRASIL, 2000).

A ausência de acessibilidade e as adversidades logísticas tornam negativa a entrada da pessoa com deficiência no mercado de trabalho. Nas organizações uma maneira de promover a acessibilidade principalmente em estabelecimentos e escritórios, é investir no ambiente laboral e na sua ergonomia, promovendo, por exemplo, adaptações para receber esses funcionários e torná-los efetivos no cotidiano. É essencial que as empresas invistam, não só em eliminar as barreiras físicas, mas também as barreiras que o preconceito pode levantar entre os funcionários, para proporcionar um ambiente de trabalho harmônico.

\section{CONSIDERAÇÕES FINAIS}

Por muitos anos, a pessoa com deficiência foi discriminada, isolada e rejeitada. Com o passar dos anos, elas foram conquistando espaço na sociedade. A aceitação, respeito e inserção da pessoa com deficiência no mercado de trabalho vem evoluindo, por meio da criação de leis e decretos, mas barreiras e dificuldades ainda existem e preocupam.

Essas dificuldades de inserção não são atuais. Os registros mais antigos, apontam que não existiam leis que favoreciam às pessoas que nasciam com deficiência e muitas delas eram eliminadas da sociedade. Nos dias de hoje, a realidade é outra,

RC: 91995

Disponível em: https://www.nucleodoconhecimento.com.br/lei/pessoa-comdeficiencia 
exemplo da criação da Lei de Cotas, que institui a exigência de organizações contratarem um percentual de pessoas com alguma deficiência.

O artigo visa compreender por que mesmo com a criação de leis, que asseguram plenos direitos às pessoas com deficiência, essas pessoas ainda encontram barreiras e obstáculos que impedem a inserção delas no mercado de trabalho. Muitos obstáculos ainda deverão ser ultrapassados como o preconceito e a ignorância, no sentido de falta de conhecimento. Mesmo com a crescente transformação da sociedade ao longo dos anos, pessoas com algum tipo de deficiência ainda sofrem com o preconceito enraizado na sociedade.

De acordo com Ribas (1996, p. 63), a ignorância não é uma característica apenas dos mais pobres ou dos que têm menos estudo. É algo que está presente em todas as camadas sociais. $\mathrm{O}$ preconceito contra pessoas com deficiência ainda impede a acessibilidade, pois mesmo com toda a legislação criada para assegurar os direitos às pessoas com deficiência, ainda existem dificuldades para que elas sejam cumpridas e respeitadas. Isso só vai acontecer a partir do momento em que a sociedade compreenda a importância da inclusão.

Em relação à falta de oportunidade de emprego e qualificação profissional, a mentalidade, principalmente das organizações, precisa mudar, evoluir, uma vez que muitas empresas ainda contratam pessoas com deficiência com foco exclusivo no cumprimento da Lei de Cotas. O medo de receber uma multa por descumprir a Lei, não deve ser maior do que o esforço para a inclusão da PcD no mercado de trabalho. É evidente que, em um país com quase $24 \%$ da população composta por pessoas que possuem algum tipo de deficiência, essas barreiras precisam cair por terra.

Este artigo se propôs identificar barreiras que dificultam o processo de inclusão das pessoas com deficiência no mercado de trabalho. Trouxe à compreensão, a jornada histórica percorrida pelo deficiente físico através dos anos. Além disto, discorreu sobre os pressupostos legais que embasam a inclusão da PcD no mercado.

RC: 91995

Disponível em: https://www.nucleodoconhecimento.com.br/lei/pessoa-comdeficiencia 
Considera-se que este artigo conseguiu atingir seu objetivo que era de compreender as principais barreiras que impedem a pessoa com deficiência de alcançar espeço no mercado de trabalho, extinguir o preconceito instaurado ao longo dos anos e contribuir para uma sociedade mais justa e igualitária.

\section{REFERÊNCIAS}

ARISTOTELES. Política. 2. ed. Brasília, DF: Editora UnB. 1985.

ARANHA, Maria Salete Fábio Aranha. Integração Social do Deficiente: Análise Conceitual e Metodológica. Temas em Psicologia, n. 2. Ribeirão Preto. Sociedade Brasileira de Psicologia, 1995. Disponível em < http://pepsic.bvsalud.org/pdf/tp/v3n2/v3n2a08.pdf> Acesso em 28 de abril de 2021.

BRASIL. Constituição (1988). Constituição da República Federativa do Brasil. Brasília, DF: Senado Federal: Centro Gráfico, 1988. Art. 23.

BRASIL. Decreto-lei № 3.298, de 20 de dezembro de 1999 - dispõe sobre Política Nacional para a Integração da Pessoa Portadora de Deficiência. Disponível em: < http://www.planalto.gov.br/ccivil_03/decreto/d3298.htm>. Acesso em 05 de maio 2021.

BRASIL. LEI 8.213, de 24 de julho de 1991 - Art. 93 - dispõe sobre Lei de Benefícios da Previdência Social. Disponível em: < http://www.planalto.gov.br/ccivil_03/leis//8213cons.htm>. Acesso em 28 de abril de 2021.

BRASIL. LEI 10.098, de 19 de dezembro de 2000 - dispõe sobre Promoção da Acessibilidade das Pessoas Portadoras de Deficiência. Disponível em: < http://www.planalto.gov.br/ccivil_03/leis/110098.htm>. Acesso em 02 de maio de 2021.

RC: 91995

Disponível em: https://www.nucleodoconhecimento.com.br/lei/pessoa-comdeficiencia 
CONVENÇÃO INTERNACIONAL SOBRE OS DIREITOS DAS PESSOAS COM DEFICIÊNCIA (CORDE). Organização das Nações Unidas (ONU). CPDP/ONU. 2007.

FERNANDES, Marcos. O Preconceito Social Contra as Pessoas com Deficiência. Disponível em <https://www.webartigos.com/artigos/o-preconceitosocial-contra-a-pessoa-com-deficiencia-algumas-implicacoes/37026/> Acesso em 05 de maio de 2021.

GUGEL, Maria Aparecida. Pessoas com Deficiência e o Direito ao Trabalho. Florianópolis: Obra Jurídica, 2007.

A Pessoa com Deficiência e sua Relação com a História da Humanidade. Ampid (associação Nacional dos Membros do ministério Público de defesa dos Direitos dos Idosos e Pessoas com Deficiência), 2015. Disponível em $<$ http://www.ampid.org.br/ampid/Artigos/PD_Historia.php>. Acesso em 10 de maio de 2021.

IBGE. Dados Sobre Pessoas com Deficiência. Disponível em < https://educa.ibge.gov.br/jovens/conheca-o-brasil/populacao/20551-pessoas-comdeficiencia.html > Acesso em 27 de maio de 2021.

MACIEL, Maria Regina Cazzaniga. Portadores de Deficiência, a Questão da Inclusão Social. Sur, Rev. Int. Direitos Humanos. São Paulo, 30 maio 2003. Disponível em: <http://www.scielo.br/scielo.php?script=sci_arttext\&pid=S0102$88392000000200008>$ Acesso em 10 de maio 2021.

PASTORE, José. Oportunidades de Trabalho para Portadores de Deficiência. Editora LTR, São Paulo, 2000. In: PASTORE, J. Oportunidades de trabalho para portadores de deficiência. São Paulo: Editora LTR, 2000.

RIBAS, J. B. C. As Pessoas Portadoras de Deficiência na Sociedade Brasileira. Brasília, DF: CORDE, 1997.

RC: 91995

Disponível em: https://www.nucleodoconhecimento.com.br/lei/pessoa-comdeficiencia 
SASSAKI, Romeu Kazumi. Vida Independente: História, Movimento, Liderança, Conceito, Reabilitação, Emprego e Terminologia. São Paulo/SP. Revista nacional de reabilitação. 2003.

\section{APÊNDICE - DE REFERÊNCIA DE NOTA DE RODAPÉ}

2. O Hospício Pedro II foi fundado em 1852, com localização no Rio de Janeiro, no bairro de Botafogo. Patrocinado pelo Imperador Dom Pedro II (REY, 2012).

3. Instituto dos Meninos Cegos foi fundado em 1854, através de um Decreto Imperial, sendo o primeiro passo para a inclusão social dos deficientes visuais brasileiros. Em 1891, recebeu um novo nome, o qual tem até hoje, Instituto Benjamim Constant, em homenagem ao seu terceiro diretor. Localizado na Cidade do Rio de Janeiro. (INSTITUTO BENJAMIM CONSTANT, 2015)

4. O Imperial Instituto de Surdos-Mudos foi inaugurado em 1856, no Rio de Janeiro, no Bairro de Laranjeiras. Atualmente, se chama Instituto Nacional de Educação de Surdos (INES, 2015).

5.

em:

<http://apps.who.int/iris/bitstream/handle/10665/44575/9788564047020_por.pdf;jsess ionid=8A684EE7DAE0EA5C4C262A738A6FF31E?sequence=4>. Página 35. Acesso em 17 de abril de 2021.

6. Disponível em < http://www.diversasolucoes.com.br/documentos/pesquisa-isocialexpectativas-e-percepcoes-sobre-o-mercado-de-trabalho-para-pessoas-comdeficiencia-2017-2018-pcds.pdf >. Acesso: 11 abril. 2021.

Enviado: Junho, 2021.

Aprovado: Julho, 2021.

RC: 91995

Disponível em: https://www.nucleodoconhecimento.com.br/lei/pessoa-comdeficiencia 